\title{
Influence of Advertising Billboard Images on Driver Performance
}

\author{
*PRAISE Woeyram Anani (Corresponding Author) \\ (Mphil. Communication Design) \\ Department of Communication Design \\ Kwame Nkrumah University of Science and Technology Kumasi - Ghana
}

\begin{abstract}
Background: The high demand for brand and brand promotion in Ghana seems to be on the rise. Advertisers are making use of every available space to promote and sell their brands, not knowing the silent contribution of some of these billboards to the occurrence of road accidents on the highways of Ghana. External distractions appear to play a major role in at least 6-9\% of distraction-affected motor vehicle collisions (MVCs). Driver inattentiveness and distraction are known to be the two main life-threatening factors for road safety globally.

Aim: The aim of this study is to explore how the visual elements (images) on billboards distract drivers and influence their performance. Although roadside advertising has been identified as a potential source of driver distraction, little attention has been given to what specifically on the billboard that causes the distraction.

Method: For the study to ascertain the influence of advertising billboard images on driver performance, a standard designed questionnaires were administered to 200 drivers at the major bus/truck terminals in Kumasi; both commercial and private drivers who ply the Kumasi -Accra highway on regular basis. Information obtained from the questionnaires was analyzed using Statistical Package for Social Sciences (SPSS). The questionnaires and also to some private car drivers.

Results: The study revealed that images on roadside advertising billboards do not only attract the driver's attention, but also influence the driver's psyche and consequently take their concentration and focus from their primary driving task. This was evident in the results where 123 (representing 61.5\%) of the respondents indicated that they get attracted to the images on the billboards more.

Conclusion: The study dealt specifically with the influence billboard images have on drivers and the road user in general. There is the need for further research to be done specifically on the type of images that advertisers should be encouraged to display on the advertising billboards.
\end{abstract}

Keywords: Driver Performance, Drivers attention, Advertising Billboards Images, Traffic Safety, Road Accidents DOI: $10.7176 / \mathrm{DCS} / 10-6-01$

Publication date: June $30^{\text {th }} 2020$

\section{Introduction}

Distraction contributes to motor vehicle crashes when a driver's attention is diverted away from the driving task at a time when the driver is required to identify and respond to an unexpected hazard or a changing driving situation (NHTSA, 2008). Driving as a transport behaviour delivers important social and economic benefits, but also poses significant risks to quality of life, including injury and death. Worldwide, over 1.2 million people die each year as a result of injuries sustained from road crashes (WHO, 2015). Road accident injuries in Ghana place a huge burden on the national economy and household finances. Many families have been deprived of breadwinners as a result of road accidents. This calls for immediate attention from all government and non-government organisations. In recent years, road accidents have been on the increase in Ghana, particularly on the Kumasi - Accra highway (Ghana Building and Road Research Institute, 2015).

The purpose of this study is to help shed light on the extent to which roadside advertising billboard images in Ghana specifically on the Kumasi - Accra highway cause driver distraction and also the consequences of any such distraction for traffic safety both directly and as a test case for external-to-vehicle distractions in general.

The Global Status Report on Road Safety conducted by World Health Organization in 2015 made a prediction that, the economic expenditure of road accidents and injuries in developing country like Ghana is between $1-2 \%$ of her gross domestic product (GDP). The African Region of the World Health Organization recorded the maximum of mortalities with a rate of 28.3 deaths per 100,000 population. They were seconded by low and middle countries of the Eastern Mediterranean region with 26.4 deaths per 100,000 population. (Road traffic injury prevention report, 2004).

From research conducted by Salim and Salimah (2005), road accidents were the ninth major cause of death in low and middle income countries. In addition, they predicted that road accidents were going to be the third major cause of deaths in these countries by the year 2020 if prevailing trend in vehicular accidents was to be allowed to continue. Although most study conducted identified billboard as an external distraction to driver performance and road safety, little or no attention is given to what exactly on the billboards distract the drivers' attention. This leaves a gap for further study to be done in order to know what exactly distract drivers on the advertising billboards. To fill this gap in literature, it was imperative for this study to be conducted to explore what element of the billboard that is most distract to drivers since billboards are made of different components; structure, 
placement, images and size.

\subsection{Methodology}

One direct approach toward understanding drivers' choices and behaviors is through questionnaires. In this research, a standard designed questionnaire instrument was developed and used to gather data. The questionnaires were administered to 200 drivers who ply the Kumasi - Accra high way on regular basis. The questionnaire included a total of 20 questions that assessed several variables of interest including exposure (driving patterns and experience, frequency of billboard encounters), driver's behaviors, attitudes, and perceptions toward billboards with respect to the type of images placed on them and tendency of distraction. Convenience sampling also known as accidental sampling is a nonprobability or nonrandom sampling where members of the target population that meet certain practical criteria, such as easy accessibility, geographical proximity, availability at a given time, or the willingness to participate are included for the purpose of the study (Ilker, Sulaiman \& Rukayya, 2016) was employed in the current study thus participants were selected based on availability at the time the researcher was there and also respondent's willingness to participate in filling the questionnaire.

\subsection{Analysis}

Information obtained from the questionnaires was analyzed using Statistical Package for Social Sciences (SPSS). SPSS was appropriate for the analysis because of its unique way of generating routine descriptive statistical data for question responses, such as frequency counts of closed questions, crosstabs and also exploring relationships between responses to different questions.

\subsection{Results}

\subsubsection{Drivers' Attraction to Billboards}

A total of 200 questionnaires were sent out and were all fully answered, this was because of the methodology adopted by the researcher. The questionnaires were administered personally only to respondent (drivers) who were willing and ready to fill out the questionnaires. The questionnaires, as indicated in the previous section, were administered between commercial drivers and private drivers within Kumasi who ply the Kumasi-Accra highway on regular basis. The results of this study uncovered the silent contribution of billboard images to the occurrence of road accidents on high ways of Ghana, using the main Kumasi-Accra highway as a case study.

Drivers who responded and participated in the study were all very experienced drivers, hence, they shared their rich experiences with the researcher. Nineteen (representing 9\%) of the respondents have been driving for less five (5) years. Forty-seven (24\%) respondents have been driving between 5 and 10 years and 134 (representing $67 \%$ ) of the drivers had driven more than ten (10) years. A descriptive statistics using crosstab analysis showed that both highly experienced and amateur drivers' still get distracted by the images placed on advertising billboards.

The results from the study revealed that, majority of the drivers get attracted to the images on advertising billboards more. To get this fact, drivers were asked specifically in the questionnaire "what attracts you to advertising billboards more". This question was very prudent since it will help the study to clearly know if really images have any influence on drivers. The findings are summarized in Figure 1.

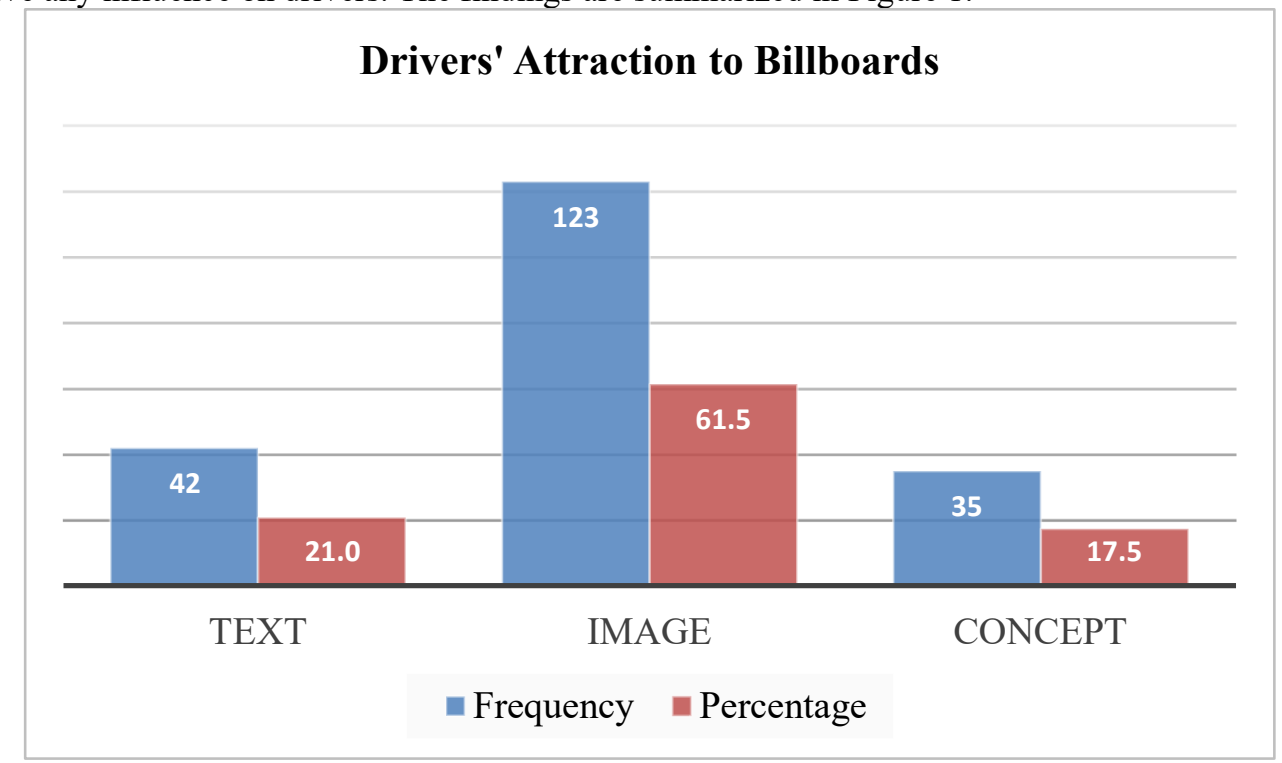

Source: Field Survey, 2019

Figure 1. Response to what attracts Drivers to Billboards

As shown in Figure 1, out of the 200 respondents, 42 (representing $21.0 \%$ ) of the respondents indicated that, 
they get attracted to the text on the billboards more, the majority 123 (representing 61.5\%) of the respondents indicated that they get attracted to the images on the billboards more. The final $35(17.5 \%)$ of the respondents indicated that they get attracted to the concept of the billboards more. The percentage of those who get attracted to the images is higher which means that, drivers are more attracted to the images placed on advertising billboards than the text, the design and concept.

\subsubsection{The Influence of Billboard Images on Drivers}

It was discovered that billboards distract drivers more compared to other items they see in their physical driving environment like tree, building and other visible items (Praise and Appiah, 2019). In the previous section, it was established that, drivers are more attracted to the images on the advertising billboards but whether the type of images placed on the billboards can influence a driver's performance is yet to be ascertained in this section. According to Edquist (2011), a possible driver distraction is the 'visual pollution' from the roadside advertisement. These roadside advertisements may not only attract the driver's attention, but also influence the driver's psyche. Chattington (2009), revealed from his study that, visual pollution has a negative impact on driver behavior. This negative impact could affect the output performance of the driver and influence their psyche as stated by Edquist (2011). To agree or disagree with Edquist (2011) and Chattington (2009) to unveil if really billboard images influence drivers' performance, the drivers were asked specifically in the questionnaire "Does what you see on advertising billboards influence how you drive" in order to establish an empirical the fact on the case. 170 (85\%) out the total 200 respondents signified that, what they see on the advertising billboards influence how they drive, whereas $30(15 \%)$ of the respondents indicated that, their driving performance does not get influenced by what they see on advertising billboards. This is a clear indication that most drivers get influenced by the images placed on advertising billboards. Though it has been established that billboard images influences drivers and distract them, it is prudent for the study to ascertain if the type of image placed on the advertising determines the amount of time they get distracted. The survey participants were asked "does the type of image on billboards determine how long you look at them". Interestingly, 177 (88\%) of the respondent confirmed that, indeed the type of images on the advertising billboards determines how long they look at them. Details of the response to this question is presented in the frequency table below.

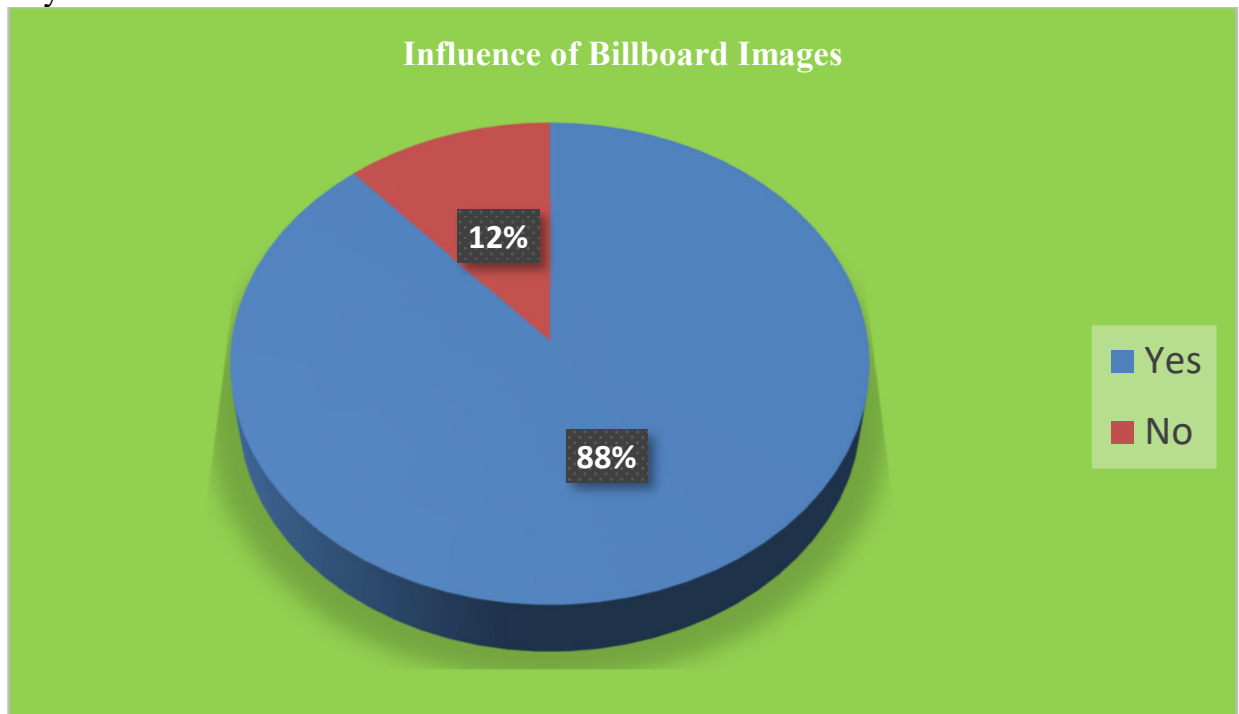

Source: Field Survey, 2019 Figure 2. Drivers’ Response to how Images on Billboards influence them

Some of the images are so attractive that it is quite difficult to take their eyes off them especially when the advert is new on the road with very seductive female images and it is within a $50 \mathrm{~km} / \mathrm{h}$ zone. However, 23 (12\%) of the respondents thought otherwise that, the type of image on the billboards does not determine how long they look at them. Some of these drivers explained in a further investigation that, because they know what will happen if they look at the images especially that, their concentration will drift away, hence they consciously decide not to look at them at all.

Another interesting finding to further establish more empirical facts to reveal billboard images influence drivers performance is the amount of time drivers spend looking at billboard images. This is necessary and would be of immense help to the study, since road accidents can occur even when drivers are distracted for five seconds while traveling at $60 \mathrm{~km} / \mathrm{h}$, then they aren't looking at the road for 100 yards or more (the length of a football field), which is more than enough time for a vehicle accident to occur (Wolch, 2008).

From the data and analysis, 57 of the respondents spend less than 30 seconds to look at billboard images. This is even too much time for road accident to occur, whereas 117 out of the 200 respondents spend between 30 second to 1 minute looking at billboard images while 26 of them spend more than 1 minute looking at billboard images 
especially in billboards which are mounted in high traffic areas. Details of the response in figure 3.

\section{Time Spent On Billboards}

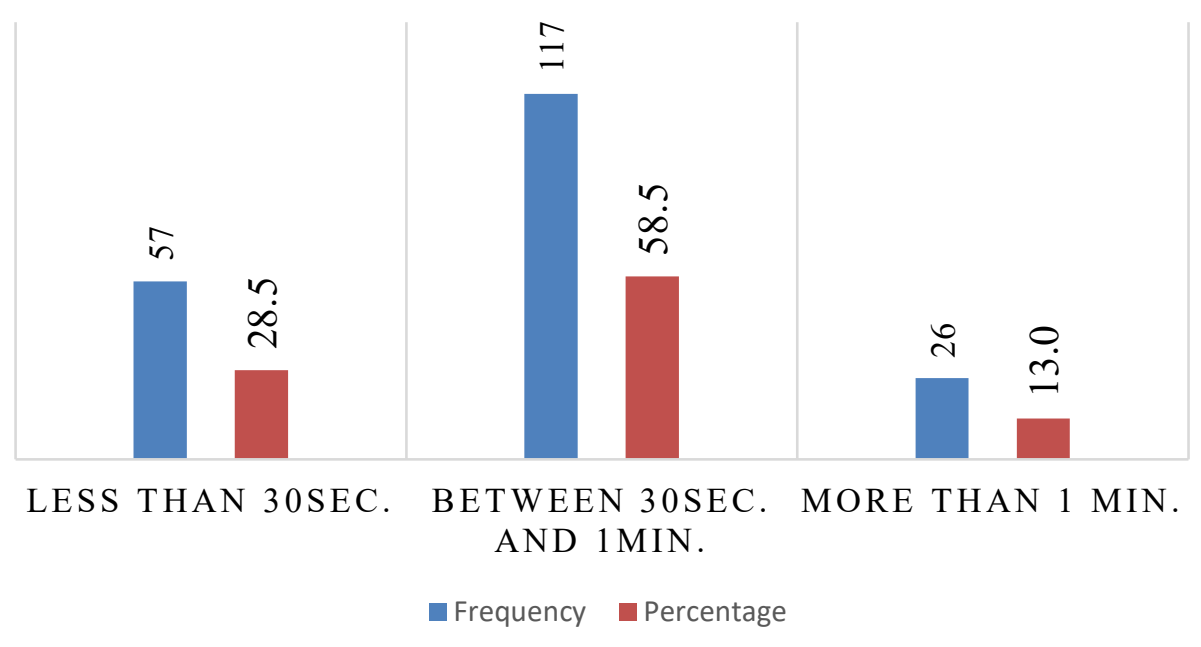

Source: Field Survey, 2019 Figure 3 Response to Time spent looking Billboards

This result is very alarming, because according to Wolch (2008), should a driver get distracted even for five seconds while traveling at 60 miles per hour, there are high chances for a vehicular accident to occur. Drivers reveal in a further investigation that, mostly these accidents occur when they miss safety signals because they are focused looking at the images placed on advertising billboards. Whereas, in this study, majority of the drivers clearly indicated that they spend more than five (5) seconds looking at these billboards. This suggests a high tendency of billboard images being the cause of many accidents that occur on our roads but unfortunately, it is not given due attention and urgency. The accident analysis in a study by Gitelman et al (2010) examined the influence of billboards on accident occurrence on the Ayalon highway in Tel Aviv Metropolitan Area. Two periods were compared: "before" - when the billboards were present along the roadside (years 2006-2007) and "after" - when the billboards were covered (2008). The results from their study show a general reduction in accidents on the Ayalon Highway after the removal of billboards. 116 (representing 55\%) of the respondents confirmed that the images on the billboard is what makes the billboards distractive to them and it is the images especially highly seductive female images that takes their attention from their primary driving task. This shows that the images placed on advertising billboards influence the performance of drivers negatively. This was ascertain when the respondents were asked specifically in the questionnaire "how do billboards distract you when you are driving".

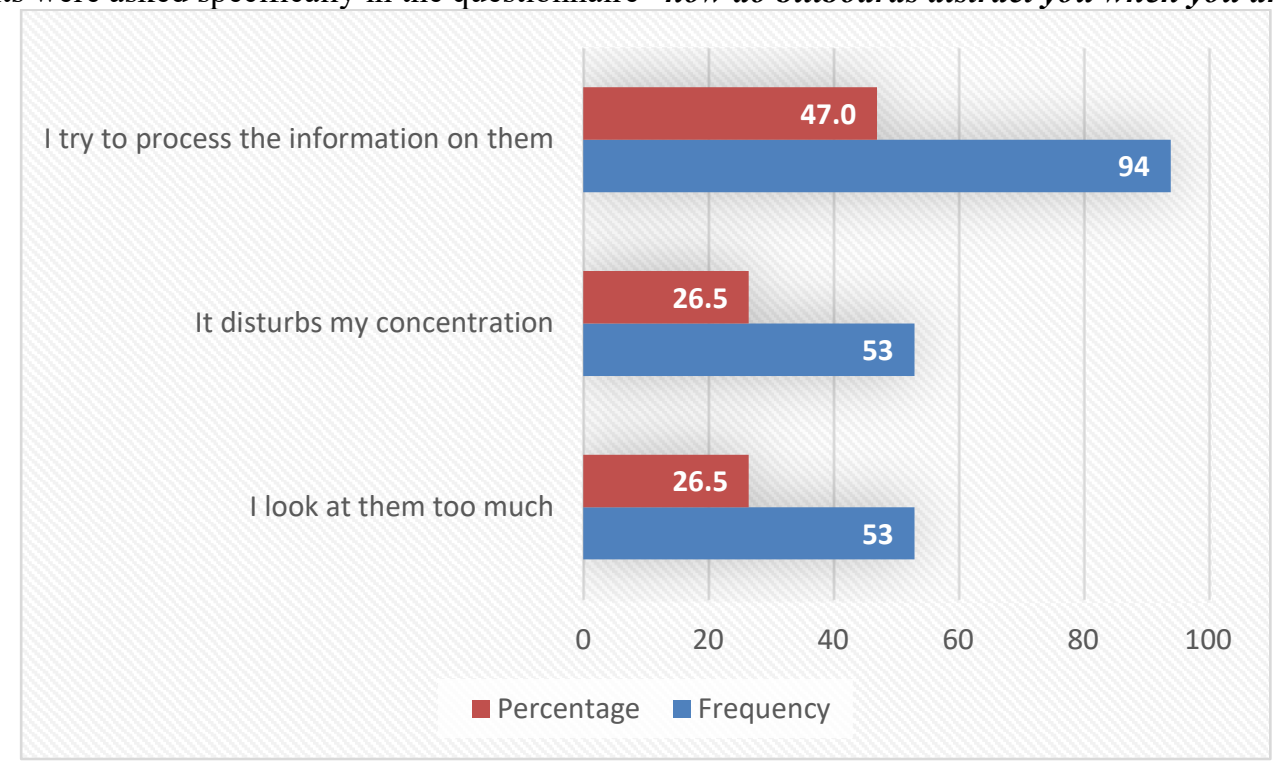

Source: Field Survey, 2019 Figure 4 Response to how billboard images distract drivers

Remarkably, 94 of the respondents (47\%) indicated that billboard images distract them when they try to process the information, 53 of the respondents indicated that, the billboard images take their concentration from the road. And the last group of respondents also $53(26 \%)$ indicated that they look at the billboard images too 
much. The various ways by which advertising billboard images distract drivers compels or tends to induce the driver's shifting attention away from the fundamental driving tasks suggest that billboards have been contributing significantly to the occurrence of road accidents silently. The results in figure 4 shows and confirms how images on billboards distract drivers and consequently lead to the occurrence of road accidents. Due to the distractions caused by the images, drivers sometimes either go off the road, hit another car or hit a pole. The study discovered that, the type of images placed on the advertising billboards determines how long the drivers look at them. This was remarkably confirmed by $177(88 \%)$ of the respondent. The findings also revealed that billboard images influence drivers and affect their concentration when they look at the images too much or try to process or understand the images placed on the billboards.

\subsection{Conclusion}

This study discovered perceived and real impacts of advertising billboard images and their influence on the performance of drivers' mostly commercial drivers who ply the Kumasi - Accra high way on daily and regular basis. This study presents a contribution to both the traffic safety research and emerging growth of advertising research as it provides some insights that can help inform future public policy relating to driver distraction and advertising billboards, especially in regards to principles and guidelines for advertising billboard use and its contents. The findings offer support to future interventions such as incorporating advertising billboard awareness into courses offered for driver education generally.

Roadside advertisements do not only attract the driver's attention, but also influence the driver's psyche. A possible driver distraction is the 'visual pollution' from the roadside advertisement. The result from the study showed that, images on advertising billboards influence drivers' performance. These images mostly take the concentration of the drivers from their primary driving task and sometimes make them unable to keep lane control and see safety signals. Advertising billboard images have negative influence on drivers and contribute largely in silence to road accidents on highways. This is as a result of the short life span of the advertising billboards, after a while of the advertising billboards being mounted it does not attract drivers anymore, hence they are changed to new ones with more attractive images meant to catch the attention of road users. This unknowingly to advertisers end up distracting and influencing the performance of drivers this is what makes billboards with highly attractive images so dangerous and distractive to drivers.

\subsubsection{Recommendations}

The study was conducted not to destroy billboard advertising and brand promotion business but rather draw attention to the silent contributions of the images placed on billboards to driver distraction that leads to road accidents. This is to help reduce driver distractions by the influence of billboard images which lead shows to be a contributing factor to the occurrence of accidents. The following recommendations are given, based on the findings from this study.

\subsubsection{For Policy Makers}

There should be effective enforcement of the rules and regulations governing outdoor advertisement and its contents. Authorities in charge of outdoor advertisement should enforce and ensure restraint in the type of images advertisers put on their billboards. They should also check the placement and sizes of the billboards. Adverting billboards with attractive and seductive images should be removed from the main Kumasi - Accra highway for a year and placed back the following to see clearly the difference in road accident records in both years. Authorities in charge of road safety should erect and place more road safety signposts along the highways.

\subsubsection{For Further Research}

The study dealt specifically with the influence billboard images have on drivers and the road user in general. There has not been enough research conducted in the area of driver distractions, billboard images, its effects and contribution to the occurrence of road accidents in Ghana. From this viewpoint; the researcher would recommend that further research be done specifically on the type of images that advertisers should be encouraged to display on the advertising billboards. This will help clarify and throw more light on the type of image that are most distractive and or if all images can potentially cause road accidents.

\section{REFERENCES}

Chattington, M., Reed, N., Basacik, D., Flint, A. \& Parkes, A. (2009). Investigating driver distraction: The effects of video and static advertising (No. CPR208). Crowthorne, UK: Transport Research Laboratory.

Edquist, J., Horberry, T., Hosking, S., \& Johnston, I. (2011). Effects of advertising billboards on simulated driving. Appl Ergon.

Gitelman V., Zaidel D. and Doveh E. (2010). Influence of Billboards on Driving Behaviour and Road Safety. Haifa

Ilker E, Sulaiman A. M., Rukayya S. A., (2016). Comparison of Convenience Sampling and Purposive Sampling, American Journal of Theoretical and Applied Statistics. Vol. 5, No. 1, pp. 1-4. doi: 10.11648/j.ajtas.20160501.11 
National Road Safety Commission, (2016). Road Traffic Crashes in Ghana: Statistic, Kumasi, Ghana

NHTSA. National Motor Vehicle Crash Causation Survey: Report to Congress. National Technical Information Service; Washington, DC: 2008. Report No. DOT HS 811059.

Praise, W. A. and Edward A. (2019). Impact of Driver Distraction and Its Effect. International Research Journal of Public Health.; 3:37.

Salim and Salimah (2005). The road Ahead: the WHO newsletter on Road Safety. Sallim and Salimah child Passenger Campaign

Wolch, P., (2008). Do Road Signs and Billboards Contribute to Vehicle Accidents? Ezine Articles [Online], Available from: www.EzineArticles.com [Accessed 5/15/2017].

WHO and World Bank. (2004). World Report on Road Traffic Injury Prevention. WHO, Geneva. 